\title{
Arterial Venography of the Dog's Leg
}

\author{
LARS BJÖRK \\ From the Department of Radiology (Director Herbert L. Abrams), Harvard Medical School and \\ the Peter Bent Brigham Hospital, Boston, Massachusetts
}

\begin{abstract}
Good visualization of the veins of the leg in the dog were obtained simply by increasing the dose to ca. $2 \mathrm{ml}$ per $\mathrm{kg}$ tissue weight of contrast agent containing $282-300 \mathrm{mg} \mathrm{I} / \mathrm{ml}$. This is equivalent to the dose used in celiac, cerebral and coronary arteriography in man. Moderate increase in flow induced by injection of roentgen contrast agents gave some improvement in the visualization of the veins. Infusions of bradykinin and attempts at reactive hyperemia did not improve the visualization of the veins.
\end{abstract}

In cerebral, mesenteric, celiac and coronary arteriography there is usually good visualization of the veins and studies of the venous phase are an important part of the examination.

This is not so in peripheral arteriography particularly of the leg where usually no or only very poor filling of the veins is seen during the standard angiographic procedure.

If satisfactory visualization of the entire venous system of the leg could be regularly achieved after arterial injection of the contrast medium it would provide a new method for phlebography of the limbs. In addition to more complete anatomical information arterial venography would also provide certain information on flow rates and distribution of flow in the venous system of the leg. This would hopefully lead to better diagnosis of venous thrombosis, venous insufficiency and other conditions involving the veins of the limbs.

In this study some techniques to improve the visualization of the veins of the leg of the dog following arterial injection of roentgen contrast agents were investigated.

\section{MATERIAL AND METHODS}

Four mongrel dogs weighing $\mathrm{ca} .20 \mathrm{~kg}$ were used. Following intravenous barbituate anesthesia and intubation one femoral artery was exposed and a red Kifa catheter intro- duced. The tip of the catheter was placed in the femoral artery on the opposite side. The weight of the leg of the dog was estimated and pure methylglucamine solutions of roentgen contrast agents (Conray $60 \%$ and Hypaque $60 \%$ ) with iodine content of $282-300 \mathrm{mg} / \mathrm{ml}$ were injected in doses of 1,2 and $4 \mathrm{ml}$ per $\mathrm{kg}$ leg weight. The rate of injection was adjusted under fluoroscopic control using the spillover flowmeter principle (1) to equal approximately the flow in the femoral artery. Angiograms of the leg were obtained using the 6 inch mode of a 10/6 inch image intensifier and a $16 \mathrm{~mm}$ cine camera operating at 50 frames/sec. In a few instances recordings on $70 \mathrm{~mm}$ films were used and in one instance $4 / \mathrm{sec}$ full size angiograms using an Elema-Schönander roll film changes were obtained. To avoid shunting in the foot pad, the foot of the dog was kept in crushed ice during the angiographies.

The effects of repeated injections of contrast agents and infusion of Bradykinin (2) into the femoral artery as well as the effect of reactive hyperemia (3) were studied.

The quality of the angiograms and particularly the visualization of veins were assessed with and without these manouvers and with varying doses of contrast agents. Changes in flow in the femoral artery were roughly determined using the spillover flowmeter principle.

\section{RESULTS}

One $\mathrm{ml} / \mathrm{kg}$ leg weight of contrast agent was used 12 times in the four dogs. In all instances the venous filling was poor.

Two $\mathrm{ml} / \mathrm{kg}$ leg weight was used 16 times and good visualization of the veins was obtained in 12 instances (Fig. 1).

Four $\mathrm{ml} / \mathrm{kg}$ leg weight was given 12 times, always with good visualization of veins.

As expected injection of roentgen contrast medium produced an increase in flow of $50-100 \%$ lasting for 1-2 $\mathrm{min}$. The moderate increase in flow was accompanied by improved visualization of the veins in six of eight experiments. In two no change was observed.

Infusion of bradykinin at the rate of 1 and 0.5 $\mu \mathrm{g} / \mathrm{min}$ produced a five to ten fold increase in flow 


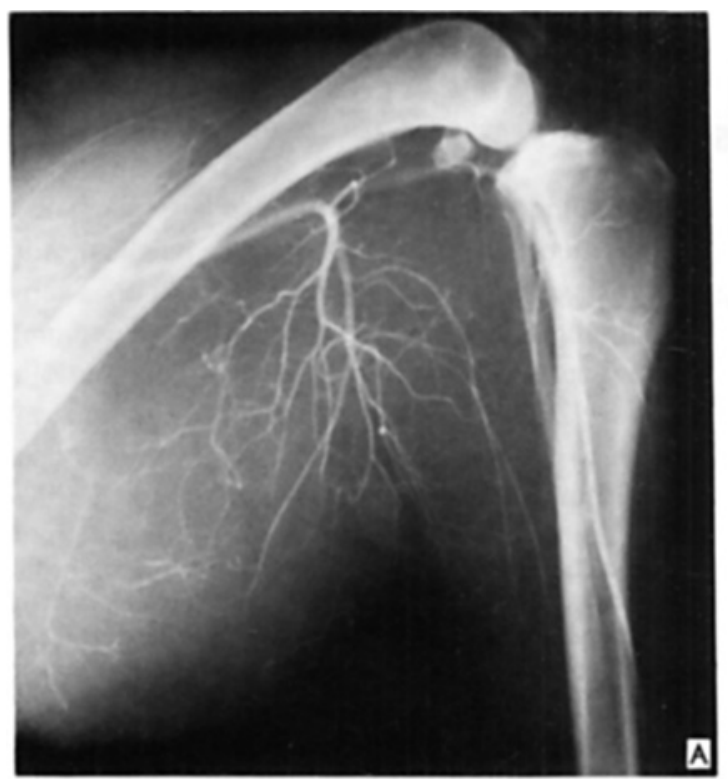

Fig. 1. Femoral artery injection of $2 \mathrm{ml} / \mathrm{kg}$ leg weight of contrast agent $(282 \mathrm{mg} \mathrm{I} / \mathrm{ml})$ in a $20 \mathrm{~kg}$ dog. (A) Late

in the external iliac artery in all of eight experiments. With the moderate dose of $2 \mathrm{ml} / \mathrm{kg}$ leg weight of contrast agent this was accompanied by a poor visualization of the veins. With a dose of 4 $\mathrm{ml} / \mathrm{kg}$ leg weight the visualization of the veins remained satisfactory.

Reactive hyperemia was attempted by manual compression of the femoral artery for $10 \mathrm{~min}$. The changes in flow following this were minimal and in all four instances no influence on the visualization of the veins was observed.

\section{DISCUSSION}

It appears that the dose of contrast agent is the major determinant for good visualization of the veins of the leg after injection into the femoral artery. A dose of ca. $2 \mathrm{ml}$ of a contrast agent containing 282-300 $\mathrm{mg}$ of iodine per $\mathrm{ml}$ produced good filling of the veins in most cases. In patients this would mean injection of $20-30 \mathrm{ml}$ of contrast into the femoral artery. This is a dose that is only $2-3$ times the standard dose used for peripheral arteriography. This dose per kg tissue weight corresponds closely to the doses used in other angiographies such as cerebral, celiac and coronary arteriography. The discomfort for the patient following injection of a larger dose of contrast agent into peripheral artery

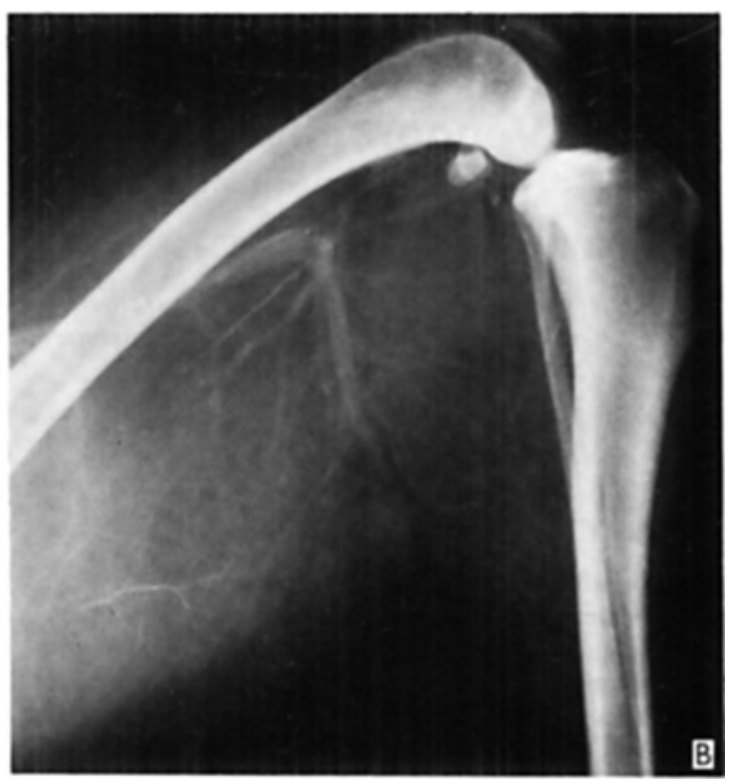

arterial phase. (B) Good visualization of the veins in the leg.

may be reduced by using only pure methylglucamine solutions of the contrast agents since these solutions are known to be less irritating than solutions containing sodium ions. In the future new contrast agents that are less toxic and less irritating than the present ones may become available $(4,5$, 6). Preliminary experiments with polymeric contrast agents with molecule weights of 15000 or 40000 showed that venous filling was regularly obtained with a dose of only $1 \mathrm{ml} / \mathrm{kg}$ leg weight of a solution containing $200 \mathrm{mg} \mathrm{I} / \mathrm{ml}$ (6). These contrast agents affect the general and local circulation less. Their lower osmotic activity leads to less dilution and they also disappear slower from the vascular bed than currently used agents.

The moderate increase in flow following injection of contrast agents was advantageous in most instances. Infusion of bradykinin increased the flow so much that larger doses of contrast medium were needed for visualization of the veins. Reactive hyperemia as applied in these experiments was ineffective. However, it is possible that occlusion of the arterial supply to the leg in combination with active muscular work may be effective in improving the venous visualization in man.

Arterial venography of the leg in man may be feasible and could be tried on an experimental basis. However, one must be aware of the many 
differences between performing these studies in dogs under general anesthesia and in patients.

\section{ACKNOWLEDGEMENT}

This work was supported in part by USPHS grant HL05832, GM18674 and HL11668.

\section{REFERENCES}

1. Olin, T. \& Redman, H.: Spillover flowmeter. A preliminary report. Acta Radiol Diagn 4: 217, 1966.

2. Erikson, U.: Peripheral arteriography during bradykinin induced vasodilation. Acta Radiol Diagn 15: 193, 1965.

3. Boijsen, E. \& Dahn, I.: Femoral arteriography during maximal blood flow. Acta Radiol Diagn 3: 543, 1965.

4. Björk, L., Erikson, U. \& Ingelman, B.: Clinical experiences with a new type of contrast medium in peripheral arteriography. Am J Roentgenol Radium Ther Nucl Med 106: 418, 1969.

5. Almén, T.: Cardiovascular effects of injection of metrizamide and other contrast media into the aortic bulb of cats. Acta Radiol, Suppl 335: 209, 1973.

6. Björk, L., Erikson, U. \& Ingelman, B.: Preliminary report on angiography with polymeric contrast agents in rabbits and dogs. To be published.

Received December 20, 1975

Address for reprints:

Lars Björk, M.D.

Department of Radiology

Sahlgren's Hospital

41345 Gothenburg

Sweden 